\title{
Assessment of embryo/fetus during pregnancy by three- dimensional ultrasonography using the HD live software: iconographic essay*
}

\begin{abstract}
Avaliação do embrião/feto ao longo da gestação por meio da ultrassonografia tridimensional com o software HD live: ensaio iconográfico
\end{abstract}

\author{
Edward Araujo Júnior ${ }^{1}$, Eduardo Félix Martins Santana ${ }^{2}$, Luciano Marcondes Machado Nardozza ${ }^{1}$, Antonio \\ Fernandes Moron ${ }^{3}$
}

Araujo Júnior E, Santana EFM, Nardozza LMM, Moron AF. Assessment of embryo/fetus during pregnancy by three-dimensional ultrasonography using the HD live software: iconographic essay. Radiol Bras. 2015 Jan/Fev;48(1):52-55.

Abstract Fetal development is studied since the advent of two-dimensional ultrasonography. However, a detailed assessment of structures and surfaces improved with three-dimensional ultrasonography. Currently, it is possible to identify embryonic components and fetal parts with greater detail, at all pregnancy trimesters, using the HD live software, where the images gain realistic features by means of appropriate control of lighting and shadowing effects. In the present study, the authors utilized this resource to follow-up, by means of images, the development of a normal pregnancy along all trimesters.

Keywords: Embryo; Fetus; Normal development; Three-dimensional ultrasonography; HD live.

Resumo O desenvolvimento fetal é estudado desde o advento da ultrassonografia bidimensional. Entretanto, a avaliação pormenorizada de estruturas e superfícies ganhou maior qualidade com a ultrassonografia tridimensional. Atualmente, é possível identificar componentes embrionários e partes do feto com maior riqueza de detalhes, em todos os trimestres da gestação, utilizando o software HD live, no qual a imagem ganha características realísticas mediante controle adequado de luz e sombreamento. Neste estudo utilizamos este recurso, por meio de imagens, para acompanhar a evolução de uma gestação normal em todos os seus trimestres.

Unitermos: Embrião; Feto; Desenvolvimento normal; Ultrassonografia tridimensional; HD live.

\section{INTRODUCTION}

The utilization of three-dimensional ultrasonography (3DUS) has gained exponential importance in the practice of prenatal diagnosis. In fact, obstetrics has developed and has gradually introduced this resource which initially was inappropriately considered to be a simple means to visualize images.

HD live is a new surface rendering technique where the operator uses an adjustable light source, creating lighting and shadowing effects which increase the depth perception ${ }^{(1)}$. With this resource, the visualization of embryonic structures and of the fetal development becomes more realistic, allow-

* Study developed at Department of Obstetrics, Escola Paulista de Medicina da Universidade Federal de São Paulo (EPM-Unifesp), São Paulo, SP, Brazil.

1. Private Docents, Associate Professors, Department of Obstetrics, Escola Paulista de Medicina da Universidade Federal de São Paulo (EPM-Unifesp), São Paulo, SP, Brazil.

2. Post graduate student, Department of Obstetrics, Escola Paulista de Medicina da Universidade Federal de São Paulo (EPM-Unifesp), São Paulo, SP, Brazil.

3. Private Docent, Full Professor, Department of Obstetrics, Escola Paulista de Medicina da Universidade Federal de São Paulo (EPM-Unifesp), São Paulo, SP, Brazil.

Mailing Address: Dr. Edward Araujo Júnior. Rua Carlos Weber, 956, ap. 113, Visage, Vila Leopoldina. São Paulo, SP, Brazil, 05303-000. E-mail: araujojred@terra. com.br.

Received August 3, 2013. Accepted after revision January 10, 2014. ing the sonographist to follow-up either the normal or altered gestational development ${ }^{(2-5)}$.

The literature describes innumerable utilities of 3DUS in the fetal evaluation ${ }^{(6,7)}$. However, the HD live provides an immeasurable range of applications, allowing for the identification of the most complex structures and even defective areas which would be missed by two-dimensional scanning.

High-quality images similar to those observed in vivo allow for the follow-up of the gradual embryonic development as well as the appropriate development of fetal limbs, genitalia, umbilical cord and face ${ }^{(8)}$. Recently, HD live showed to be an appropriate technique to evaluate the fetal behavior ${ }^{(9)}$.

In the present essay, the authors present 3D images depicting the normal development of an embryo/fetus, utilizing the HD live software over the three gestational trimesters, highlighting the high definition of fetal parts images and the degree of detailing of the different imaging planes.

\section{MATERIALS AND METHODS}

Retrospective, cross-sectional study with pregnant women in the age range between 28 and 32 year, and at gestational ages ranging from 6 to 37 weeks. All the women were patients at ambulatory of the Department of Obstetrics, Escola Paulista de Medicina - Universidade Federal de São Paulo (EPM-Unifesp), São Paulo, SP, Brazil, and all the 
fetuses did not present with any malformation at conventional ultrasonography. The 3D images were obtained with the objective of increasing the maternal-fetal interaction ${ }^{(10)}$, and the pregnant women participated in several studies on 3DUS developed at the Division of Fetal Medicine in the period from May 2012 to May 2013. All of such studies were approved by the Unifesp Committee for Ethics in Research.

All the US scans were performed at the 3DUS Unit, in a Voluson E8 Expert apparatus (General Electric Medical System; Zipf, Austria) equipped with convex (RAB 4-8L) and intracavitary multifrequency (RIC 6-12) transducers. Opening angles between $10^{\circ}$ and $85^{\circ}$ with regular scanning velocity (four seconds) were utilized for volumes capture. All the scans were performed by a single observer (EAJ), with 7 -year experience in obstetric 3DUS. The volumes were stored in the apparatus memory and later transferred into a personal computer (PC) and processed by the 4D Views software 10.0 (General Electric Medical System; Zipf, Austria). Mean acquisition time, including the two-dimensional evaluation and capture of 3D volumes was 45 minutes and the lighting and shadowing effects were rigorously utilized in order to create a realistic effect.

\section{RESULTS AND DISCUSSION}

Eleven volumes of different women at several gestational ages were selected. The minimum gestational age was 6 weeks and the maximum, 37 weeks and one day.

The HD live software allowed for the acquisition of extraordinary realistic images of the embryo/fetus development over the whole gestational period. The images allowed for following-up the development of embryonic annexes, limbs and face during the first trimester (Figures 1 and 2). Characterization of the face and appropriate neural tube closure was performed at the second gestational trimester (Figures 3 and 4). At the third trimester, the software allowed for higher definition of the ears implantation, facial structure, feet development and positioning, and even the fetal hair identification (Figures 5 and 7). The study of the genital morphology was realistic for both female and male fetuses (Figure 6).

The fetuses were assessed for a single time, both by 2D and 3DUS. No malformation was observed, but postnatal results were not obtained.

3DUS was introduced in the middle of the decade of 1990 , and currently is widely applied in the area of obstet-

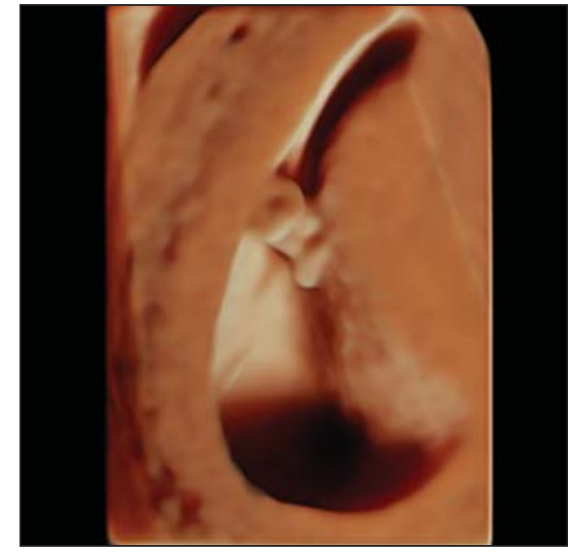

Figure 1. 3D HD live rendered transvaginal ultrasonography image of an embryo and vitelline vesicle with gestational age of 6 weeks and 6 days. Luminous incidence -5 hours.

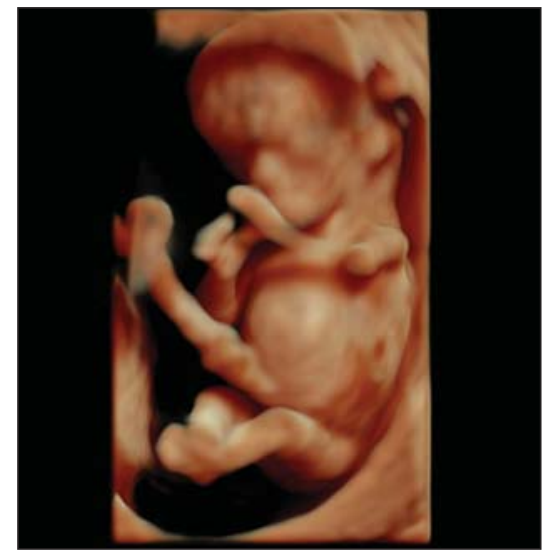

Figure 2. 3D HD live rendered image of a fetus at the 11th gestational week. The anatomy of the face and the appropriate development of the limbs can be clearly identified. Luminous incidence -1 hour.

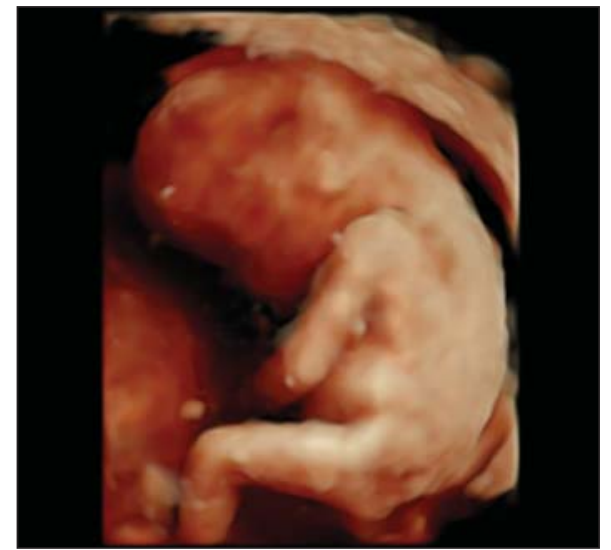

Figure 3. 3D HD live rendered image of a fetus at the 15 th gestational week. The appropriate closure of the neural tube and the correct positioning of the years can be clearly observed. Luminous incidence -1 hour.

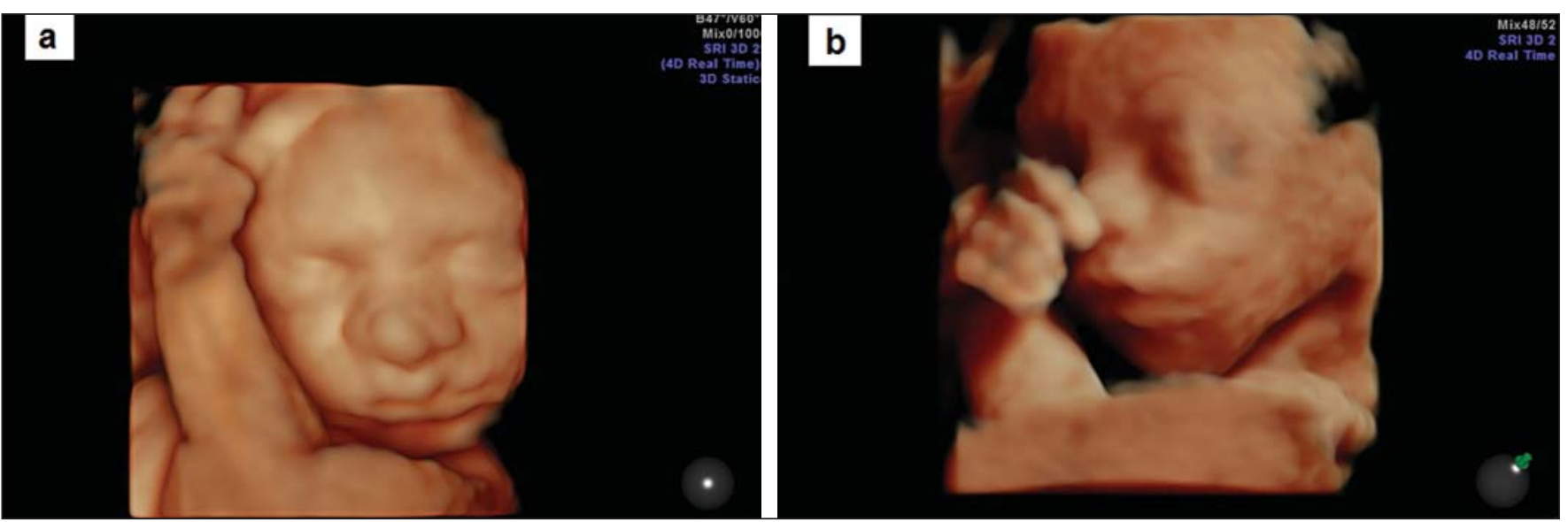

Figure 4. 3D HD live rendered image of two fetuses with gestational age of 24 weeks and 3 days. The integrity of the facial structures is observed. Central luminous incidence (a) and 1 hour (b). 

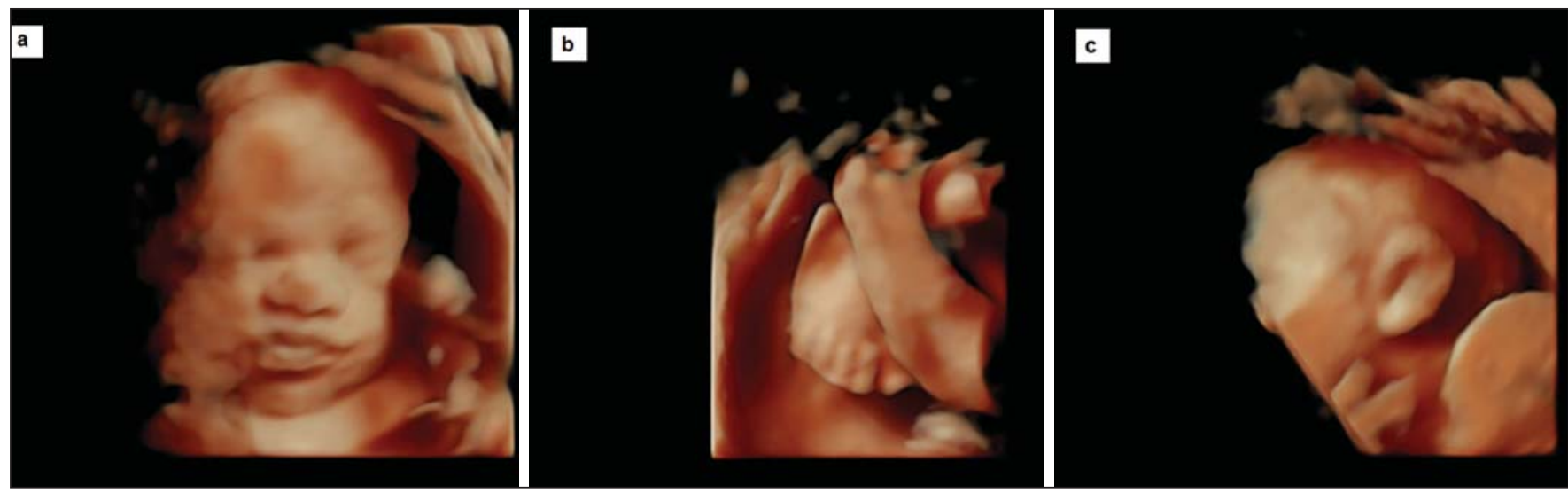

Figure 5. 3D HD live rendered image of three fetuses with gestational age of 30 weeks and 4 days. A clear detailing of the face is observed (a: luminous incidence 1 hour); feet positioning (b: luminous incidence - 11 hours) and ears positioning (c: luminous incidence - 11 hours).

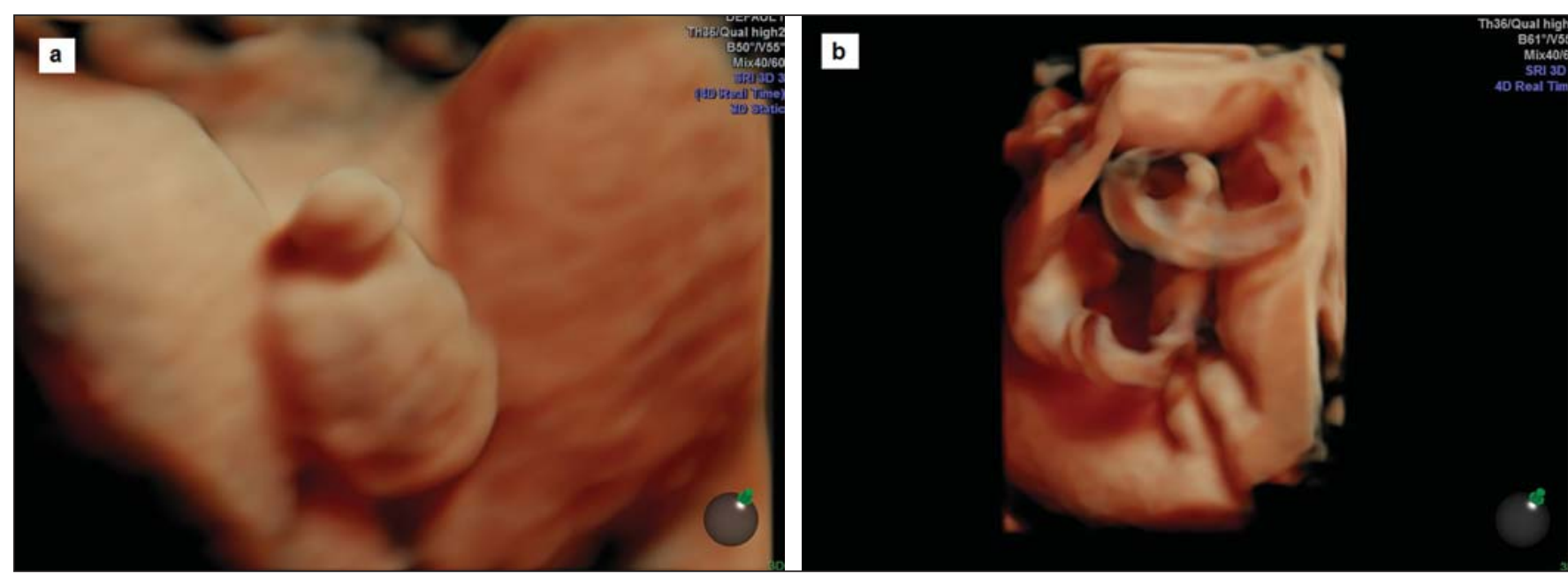

Figure 6. 3D HD live rendered image of male external genitalia of a fetus with gestational age of 30 weeks and 4 days (a: luminous incidence - 1 hour) and female external genitalia of a fetus with gestational age of 37 weeks and 1 day (b: luminous incidence -1 hour).

rics to evaluate fetal malformations ${ }^{(11,12)}$, fetal limbs volume $^{(13)}$ and fetal structures vascularization by means of $3 \mathrm{D}$ Doppler ${ }^{(14)}$.

In the present essay, the authors present the normal embryonic/fetal development over the gestation by means of 3DUS with the aid of the HD live software. Hata et al. ${ }^{(8)}$ have evaluated the development of 18 normal embryos/fetuses and 21 embryos/fetuses with malformations, and observed that, for the normal cases, the HD live provided a clear evaluation of the embryonic development through the pregnancy at the first trimester while, at the second trimester, it allowed a realistic visualization of fetal facial expressions. Tonni et al. ${ }^{(15)}$ have described a technique to evaluate the soft palate by means of 3DUS with the HD live software, utilizing the uvula as a reference. Recently, Hata et al. ${ }^{(9)}$ described the facial expression patterns by means of the HD live in 23 normal fetuses between 18 and 26 weeks. Such authors observed that this new software has allowed for a much more detailed evaluation of facial movements such as wink, murmur, swallow, yawn, suck and smile than with the conventional 3DUS.

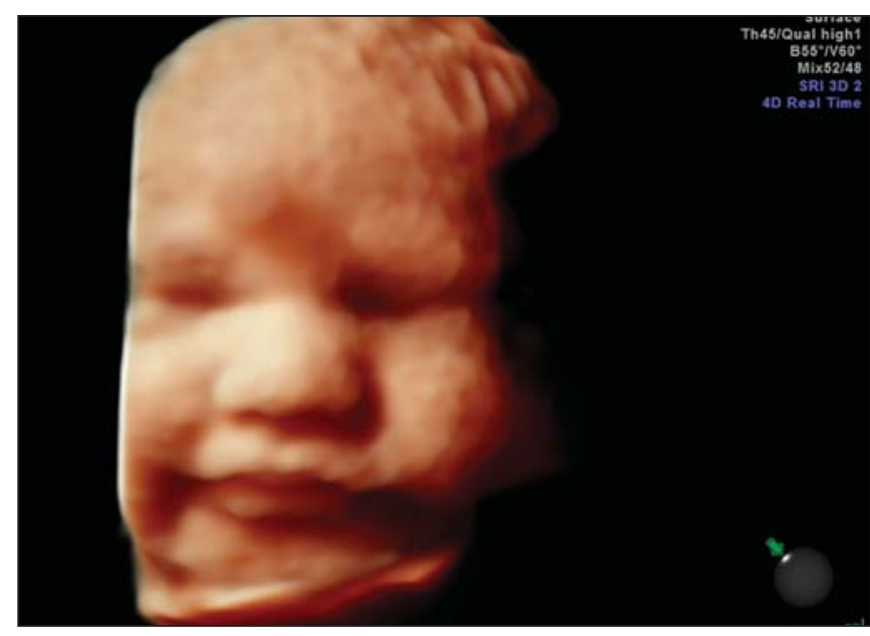

Figure 7. 3D HD live rendered image of two fetuses with gestational age of 33 weeks and 5 days. The presence of fetal hair is observed. Luminous incidence 11 hours.

\section{CONCLUSIONS}

The 3DUS scan optimized with the HD live software allows for the noninvasive acquisition of realistic images similar to those acquired during embryo-fetoscopy. Even the 
fetal skin appearance is very similar to the presential anatomical condition. The surface-rendering mode of this technique has allowed an evaluation in great detail of the fetal surface and structures, contributing for a correct evaluation of the fetal development and diagnosis during the gestation. However, the 2D approach should not be discarded; it should rather remain as the gold standard in the evaluation of the fetal development and growth as well as in the diagnosis of malformations. In the authors' opinion, in addition to future refinements of the technique, many lines of research will become feasible with 3DUS and the HD live technique.

\section{REFERENCES}

1. Kagan KO, Pintoffl K, Hoopmann M. First-trimester ultrasound images using HDlive. Ultrasound Obstet Gynecol. 201 1;38:607.

2. Hata T. HDlive rendering image at 6 weeks of gestation. J Med Ultrasonics. 2013;40:495-6.

3. Merz E. Surface reconstruction of a fetus $(28+2 \mathrm{GW})$ using HDlive technology. Ultraschall Med. 2012;33:211.

4. Hata T, Hanaoka U, Tenkumo C, et al. Three-dimensional HDlive rendering image of cystic hygroma. J Med Ultrasonics. 2013;40: 297-9.

5. Tenkumo C, Tanaka H, Ito $\mathrm{T}$, et al. Three-dimensional HDlive rendering images of the TRAP sequence in the first trimester: reverse end-diastolic umbilical artery velocity in a pump twin with an adverse pregnancy outcome. J Med Ultrasonics. 2013;40:293-6.

6. Zanforlin Filho SM, Araujo Júnior E, Guimarães Filho HA, et al.
Sonoembryology by three-dimensional ultrasonography: pictorial essay. Arch Gynecol Obstet. 2007;276:197-200.

7. Merz E, Abramovicz J, Baba K, et al. 3D imaging of the fetal face recommendations from the International 3D Focus Group. Ultraschall Med. 2012;33:175-82.

8. Hata T, Hanaoka U, Tenkumo C, et al. Three- and four-dimensional HDlive rendering images of normal and abnormal fetuses: pictorial essay. Arch Gynecol Obstet. 2012;286:1431-5.

9. Hata T, Hanaoka U, Mashima M, et al. Four-dimensional HDlive rendering image of fetal facial expression: a pictorial essay. J Med Ultrasonics. 2013;40:437-41.

10. Rustico MA, Mastromatteo C, Grigio M, et al. Two-dimensional vs. two- plus four-dimensional ultrasound in pregnancy and the effect on maternal emotional status: a randomized study. Ultrasound Obstet Gynecol. 2005;25:468-72.

11. Barros ML, Fernandes DA, Melo EV, et al. Central nervous system malformations and associated defects diagnosed by obstetric ultrasonography. Radiol Bras. 2012;45:309-14.

12. Araujo Júnior E, Simioni C, Nardozza LMM, et al. Prenatal diagnosis of Beckwith-Wiedemann syndrome by two- and three-dimensional ultrasonography. Radiol Bras. 2013;46:379-81.

13. Cavalcante RO, Araujo Júnior E, Nardozza LMM, et al. Reproducibility of fetal limbs volume by three-dimensional ultrasonography utilizing the XI VOCAL method. Radiol Bras. 2010;43:219-23.

14. Moron AF, Milani HJF, Barreto EQS, et al. Analysis of three-dimensional power Doppler sonography reproducibility in the assessment of fetal brain circulation. Radiol Bras. 2010;43:369-74.

15. Tonni G, Grisolia G. Fetal uvula: navigating and lightening the soft palate using HDlive. Arch Gynecol Obstet. 2013;288:239-44. 